\title{
The nitric oxide response in plant-associated endosymbiotic bacteria
}

\author{
Juan J. Cabrera*, Cristina Sánchez*, Andrew J. Gates†, Eulogio J. Bedmar*, Socorro Mesa*, David J. Richardson† and \\ María J. Delgado*1 \\ "Estación Experimental del Zaidín, CSIC, P.0. Box 419, 18080 Granada, Spain, and †School of Biological Sciences, University of East Anglia, Norwich NR4 7TJ, \\ U.K.
}

\begin{abstract}
Nitric oxide (NO) is a gaseous signalling molecule which becomes very toxic due to its ability to react with multiple cellular targets in biological systems. Bacterial cells protect against NO through the expression of enzymes that detoxify this molecule by oxidizing it to nitrate or reducing it to nitrous oxide or ammonia. These enzymes are haemoglobins, c-type nitric oxide reductase, flavorubredoxins and the cytochrome $c$ respiratory nitrite reductase. Expression of the genes encoding these enzymes is controlled by NO-sensitive regulatory proteins. The production of NO in rhizobia-legume symbiosis has been demonstrated recently. In functioning nodules, NO acts as a potent inhibitor of nitrogenase enzymes. These observations have led to the question of how rhizobia overcome the toxicity of NO. Several studies on the NO response have been undertaken in two non-dentrifying rhizobial species, Sinorhizobium meliloti and Rhizobium etli, and in a denitrifying species, Bradyrhizobium japonicum. In the present mini-review, current knowledge of the NO response in those legume-associated endosymbiotic bacteria is summarized.
\end{abstract}

\section{Introduction}

Nitric oxide $(\mathrm{NO})$ is a reactive free radical that plays important roles in diverse physiological processes, serving as a signalling molecule in response to biotic and abiotic stresses. At the ecological level, it has an important role as an obligatory intermediate in the respiratory pathway denitrification. NO reacts with a wide range of cellular targets, including lipids, metal centres in proteins, protein tyrosines and thiols, and DNA [1]. Thus organisms that are exposed to $\mathrm{NO}$ require activities that detoxify $\mathrm{NO}$. In bacteria, several enzymes have been shown to detoxify $\mathrm{NO}$ by oxidizing it to nitrate or reducing it to ammonia or nitrous oxide $\left(\mathrm{N}_{2} \mathrm{O}\right)$. These enzymes are Nor (nitric oxide reductase), sdHbs (single-domain haemoglobins), trHbs (truncated haemoglobins), FHbs (flavohaemoglobins), FlRd (flavorubredoxin) and cytochrome $c$ respiratory nitrite reductase (Nrf) [2-7].

In bacteria, the existence of regulatory proteins that, in the presence of NO, switch on the expression of genes encoding enzymes that detoxify $\mathrm{NO}$ has also been demonstrated. Among them, the transcription factors of the FNR (fumarate and nitrate reductase regulatory protein)/CRP (cAMP receptor protein) family, such as the Dnr and NnrR (nitrite

Key words: Bradyrhizobium japonicum, denitrification, nitric oxide, Rhizobium etli, Sinorhizobium meliloti

Abbreviations used: $\mathrm{CNor}$, cytochrome c-type nitric oxide reductase; CRP, CAMP receptor protein ETC, electron-transport chain; FHb, flavohaemoglobin; FIRd, flavorubredoxin; FNR, fumarate and nitrate reductase regulatory protein; LbNO, nitrosyl-leghaemoglobin; Nor, nitric oxide reductase; NOS, nitric oxide synthase; NR, nitrate reductase; sdHb, single-domain haemoglobin; SNP, sodium nitroprusside; trHb, truncated haemoglobin.

${ }^{1}$ To whom correspondence should be addressed (email mdelgado@eez.csic.es). and nitric oxide reductase regulator)-like proteins respond to $\mathrm{NO}$ and control expression of nir and nor denitrification genes $[6,8]$. In the non-denitrifying bacterium Escherichia coli, FNR is a sensor of molecular $\mathrm{O}_{2}$ that can be inactivated by $\mathrm{NO}$ by the formation of dinitrosyl-iron complexes as result of the reaction of $\mathrm{NO}$ with the [Fe-S] cluster [9]. NorR is another regulator that activates transcription of three different enzymes that act on NO detoxification (Nor, FlRd and FHbs) $[6,8,10,11]$. NsrR is a NO-sensitive repressor that, like NorR, regulates expression of the three dedicated NOmetabolizing enzymes (Nor, FlRd and FHbs) in different species $[6,8,12]$.

Bacterial members of the order Rhizobiales, collectively referred to as rhizobia, have the ability to establish a dinitrogen $\left(\mathrm{N}_{2}\right)$-fixing symbiosis on legume roots and on the stems of some aquatic legumes producing specialized structures called nodules [13]. Inside these nodules, bacteria differentiate into bacteroids which induce the synthesis of the nitrogenase complex that catalyses the biological reduction of $\mathrm{N}_{2}$ to ammonia. Many rhizobial species have genes for enzymes of some or all of the reactions for denitrification which comprises the reduction of nitrate $\left(\mathrm{NO}_{3}^{-}\right)$or nitrite $\left(\mathrm{NO}_{2}{ }^{-}\right)$to $\mathrm{N}_{2}$, via the gaseous intermediates $\mathrm{NO}$ and $\mathrm{N}_{2} \mathrm{O}$. The enzymes involved in denitrification are nitrate, nitrite, nitric oxide and nitrous oxide reductases encoded by nar/nap, nir, nor and nos genes respectively. In fact, denitrification can be observed in free-living rhizobia forms and in legume root nodules (for reviews, see [14-17]).

$\mathrm{NO}$ is produced in functional nodules of legume plants [18-21]. NO synthesis in plants has been reported to occur via different routes such as $\mathrm{NR}$ (nitrate reductase), $\mathrm{NO}_{2}{ }^{-} \mathrm{-NO}$ reductase, mitochondrial ETC (electron-transport chain), 
NOS (nitric oxide synthase)-like, non-enzymatic reduction and, potentially, as yet unidentified polyamine oxidation pathway (for reviews, see [22,23]). In legume plants, a NOS-like activity has been identified in nodules of Lupinus albus [24]. Furthermore, a NOS inhibitor ( $N$-methyl-Larginine) impaired $\mathrm{NO}$ detection in Medicago truncatula nodules [18], suggesting that a NOS-like enzyme may participate to NO production in nodules. Recent studies have found that plant NR and the ETC are involved in NO synthesis in $M$. truncatula nitrogen-fixing nodules ([25], reviewed in [16]). Rhizobial denitrification in the bacteroids is also a likely source of NO in nodules [19,21,25]. There is increasing evidence of the requirement of NO for an optimal establishment of the $M$. truncatula-Sinorbizobium meliloti symbiotic interaction $[20,26]$. In $\mathrm{N}_{2}$-fixing nodules, a direct inhibition of nitrogenase activity by $\mathrm{NO}$ has been demonstrated $[21,27,28]$, which suggests that modulation of NO levels in rhizobia might be necessary for an efficient symbiosis. In contrast with all that has been carried out in other bacterial species, the response of rhizobia to the presence of NO has been poorly documented. The present article provides a brief review of what is known so far about the response to NO in $S$. meliloti (Ensifer), Rbizobium etli and Bradyrbizobium japonicum.

\section{Sinorhizobium meliloti}

$S$. meliloti is an alphaproteobacterium able to establish symbiotic associations with legume plants of the genera Medicago, Melilotus and Trigonella, which includes species of great agronomic interest such as alfalfa or the model legume $M$. truncatula. The $S$. meliloti genome consists of three replicons: a $3.65 \mathrm{Mb}$ chromosome, and $1.35 \mathrm{Mb}$ pSymA and $1.68 \mathrm{Mb}$ pSymB megaplasmids. S. meliloti contains the complete set of denitrification genes (nap, nirK, nor and nos) in pSymA. However, it is considered a partial denitrifying bacterium since it is not able to grow anaerobically with $\mathrm{NO}_{3}{ }^{-}$or $\mathrm{NO}_{2}{ }^{-}$as respiratory substrates. In symbiotic $M$. truncatula nodules, recent findings have demonstrated that S. meliloti napA and nirK denitrification genes contribute to nitric oxide production [25]. However, the role of $S$. meliloti denitrification genes under free-living conditions is not known.

A powerful approach to investigating bacterial responses to nitrosative stress is to measure the global changes in gene expression that occur upon exposure to such stress. This has been used to study the nitrosative stress responses of S. meliloti [29]. Transcriptomic analyses showed that approximately 100 genes were up-regulated by NO. At least $70 \%$ of those genes up-regulated by $\mathrm{NO}$ had been described previously as being induced under microaerobic conditions [30]. Most of the genes common to the NO and microoxia stimulons are regulated by the two-component system FixLJ (i.e. nifA, fixK and smc03253) (Figure 1). The low $\mathrm{O}_{2}$ signal is perceived by the FixL histidine kinase that autophosphorylates and then transfers the phosphoryl group to the response regulator FixJ which activates transcription of FixK and NifA regulators responsible for the activation of fix genes (respiration) and nif genes $\left(\mathrm{N}_{2}\right.$ fixation) respectively [30]. In S. meliloti, FixLJ responds to both micro-oxic conditions and the presence of NO (Figure 1). It has been shown that FixL can bind ligands other than $\mathrm{O}_{2}$ such as $\mathrm{NO}$ or CO. Although the affinity of FixL is higher for $\mathrm{NO}$ than for $\mathrm{O}_{2}$, the only molecule able to abolish FixL kinase activity is $\mathrm{O}_{2}$ [31]. The higher affinity of FixL for $\mathrm{NO}$ than for $\mathrm{O}_{2}$ could explain the on-state of the kinase in the presence of NO. However, the biological relevance of the FixLJ response to $\mathrm{NO}$ in $S$. meliloti remains to be established. S. meliloti $\mathrm{NnrR}$ is also involved in the $\mathrm{NO}$ response. In this bacterium, the FNR/CRP regulators NnrR and FixK are part of two different NO-responsive signalling pathways (Figure 1). In the presence of $\mathrm{NO}, \mathrm{NnrR}$ regulates an operon (sma1289-1294) whose function is yet unknown [32]. Recent transcriptomic studies confirmed those findings and identified denitrification genes (nirK and nor C), as well as other genes related to denitrification (azu1, hemN, nnrU and $n n r S)$ as NnrR targets [29].

Among the genes induced by $\mathrm{NO}$, it is interesting to mention the $h m p$ gene encoding a $\mathrm{FHb}(\mathrm{Hmp})$ [29]. Microarray analyses showed that $h m p$ is a target of FixJ. However, the involvement of FixK as an intermediate transcriptional activator of this gene needs to be demonstrated. In S. meliloti, hmp is clearly involved in NO response, because null mutants in this gene displayed a higher sensitivity to NO compared with the wild-type, whereas overexpression of $h m p$ enhanced NO resistance [29]. Furthermore, this gene and NO play a role during the symbiotic interaction between $S$. meliloti and $M$. truncatula because nodules produced by hmp-null mutants displayed lower $\mathrm{N}_{2}$-fixation efficiency than those produced by the wild-type strain. The Hmp enzyme consists of two domains, an N-terminal haem-binding globin domain and a $\mathrm{C}$-terminal FAD- and $\mathrm{NAD}(\mathrm{P}) \mathrm{H}$-binding reductase domain, which are both required for $\mathrm{NO}$ detoxification. Hmp protects against NO both aerobically and anaerobically. Under anaerobiosis, $\mathrm{FHb}$ have a slow $\mathrm{NO}$ reductase activity which converts $\mathrm{NO}$ into $\mathrm{N}_{2} \mathrm{O}$ and might not be sufficient to protect against $\mathrm{NO}$ [33]. In the presence of $\mathrm{O}_{2}$, the enzyme, using an electron from $\mathrm{NAD}(\mathrm{P}) \mathrm{H}$ delivered via the flavin protein, catalyses a denitrosylase ('dioxygenase') reaction in which $\mathrm{NO}$ is stoichiometrically converted into $\mathrm{NO}_{3}{ }^{-}[34,35]$. Because micro-oxic conditions prevail inside nodules, detoxification of $\mathrm{NO}$ by $\mathrm{Hmp}$ could lead to the formation of either $\mathrm{NO}_{3}{ }^{-}$or $\mathrm{N}_{2} \mathrm{O}$, which may enter the denitrification pathway. These results propose the $S$. meliloti $\mathrm{FHb}$ as a significant NO-detoxifying protein in $M$. truncatula nodules which, together with plant haemoglobins, might participate in limiting NO toxicity inside nodules.

\section{Rhizobium etli}

$R$. etli establishes symbiotic associations with plants of the Phaseolus genus. The genome of $R$. etli CFN42 contains a chromosome and six large plasmids (pCFN42a to pCFN42f) 
Figure 1| N0 signalling regulatory cascades in S. meliloti, R. etli and B. japonicum Schemes are based on data from [16]

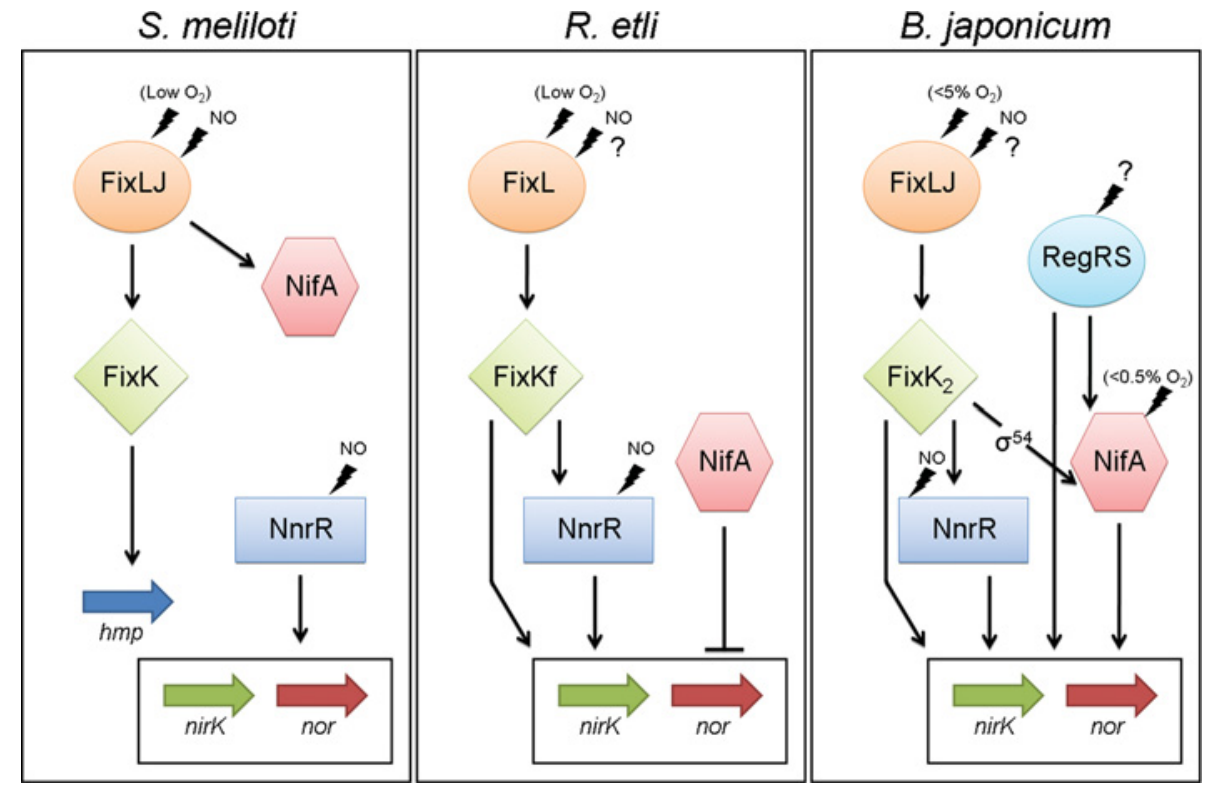

whose sizes range from 184.4 to $642.5 \mathrm{~kb}$ [36]. Plasmid d corresponds to the symbiotic one ( $\mathrm{pSym}$ ) and contains several genes involved in nodulation and $\mathrm{N}_{2}$-fixation processes. However, some important regulatory elements, such as fix $L$ and $f i x J$, are not encoded on this replicon. In $R$. etli, it is the largest plasmid, pCFN42f, which includes regulatory genes such as fixK and the fixL. In contrast with $S$. meliloti or B. japonicum, the transcriptional activator with functional homology with FixJ remains to be described in $R$. etli. Plasmid pCFN42f also contains a gene cluster with some denitrification genes such as nirK, nor $C B Q D$ and $a z u P f$ coding for a copper-containing nitrite reductase, a cNor (cytochrome $c$-type nitric oxide reductase) and pseudoazurin respectively $[36,37]$. In the nir $K-$ nor $C$ region is also located the $n n r R$ gene which encodes NnrR, the FNRtype transcriptional regulator of denitrification genes.

$R$. etli lacks part of the denitrification pathway (nap or nar and nos genes) and is unable to use $\mathrm{NO}_{3}{ }^{-}$for respiration and lacks NR activity. In contrast, it shows NR activity and $\mathrm{NO}_{2}{ }^{-}$uptake under anaerobic conditions which are highly diminished in a nirK mutant [38]. The presence of NirKand NorC-coding regions in this bacterium suggests an NOdetoxifying role for these enzymes, preventing accumulation of $\mathrm{NO}$ inside the free-living cells or in the nodules.

Recently, Gómez-Hernández et al. [39] have demonstrated the in vivo relevance of the enzymes encoded by the nirK and nor $C$ genes by exploring the response of the corresponding mutants to both $\mathrm{NO}_{2}{ }^{-}$and to NO generators, such as SNP (sodium nitroprusside). Under microaerobic conditions, a nirK-deficient strain was unable to produce $\mathrm{NO}$ from $\mathrm{NO}_{2}{ }^{-}$ and a nor $C$ mutant was defective in $\mathrm{NO}$ consumption activity, compared with wild-type cells. Moreover, the nor $C$ mutant failed to grow under microaerobic conditions in the presence of $100 \mu \mathrm{M} \mathrm{SNP}$ or $30 \mu \mathrm{M} \mathrm{NaNO}_{2}$. These data clearly indicate that $R$. etli NorC is required in vivo to detoxify $\mathrm{NO}$ under free-living conditions.

In $R$. etli, microaerobic expression of nirK and nor $C$ promoters requires a functional FixKf, whereas the response to NO is mediated by NnrR (Figure 1). In contrast with $S$. meliloti, where nirK and nor $\mathrm{C}$ are fully dependent on $\mathrm{NnrR}$, in $R$. etli full expression of nor $C$ in response to nitrogen oxides and microaerobiosis requires the presence of FixKf and NnrR, but microaerobic expression of nirK is still observed in an $n n r R$ mutant background. Although NnrR and FixK are part of two different NO-responsive signalling pathways in $S$. meliloti, in $R$. etli microaerobic expression of $n n r R$ is controlled by FixKf (Figure 1). Additionally, the $\mathrm{N}_{2}$-fixation regulator NifA has a negative effect on the transcription of the $\operatorname{nirK}$ operon [39].

Expression of nirK and nor $C$ genes has been observed in common bean (Phaseolus vulgaris) nodules by using qRT-PCR (quantitative real-time PCR). NO production has been shown in common bean nodules by measuring LbNO (nitrosyl-leghaemoglobin) complexes. As has been demonstrated previously in soya bean (Glycine max) nodules, bacterial NirK is an important contributor to the formation of $\mathrm{NO}$ in common bean nodules in response to $\mathrm{NO}_{3}{ }^{-}$, since levels of $\mathrm{LbNO}$ complexes in nodules exposed to $\mathrm{NO}_{3}{ }^{-}$increased in those produced by the nor $\mathrm{C}$ mutant, but decreased in nirK nodules compared with LbNO levels detected in wild-type nodules [39]. Interestingly, the $\mathrm{NO}_{3}{ }^{-}$induced decline in nitrogenase-specific activity observed in both the wild-type and the nor $C$ nodules was not detected in nirK nodules. 


\section{Bradyrhizobium japonicum}

B. japonicum is able to establish symbiotic associations with leguminous plants, including soya bean. Unlike the previous two examples, $B$. japonicum itself is a denitrifying organism, capable of growing anaerobically with $\mathrm{NO}_{3}{ }^{-}$as a terminal electron acceptor and of reducing $\mathrm{NO}_{3}{ }^{-}$to $\mathrm{N}_{2}$. In this bacterium, denitrification depends on the nap $E D A B C$, nirK, nor $C B Q D$ and nosRZDFYLX genes encoding the nitrate, nitrite, nitric oxide and nitrous oxide reductases respectively [14]. B. japonicum nor $C$ or nor $B$ mutants are defective in anaerobic growth under $\mathrm{NO}_{3}{ }^{-}$-respiring conditions and accumulate $\mathrm{NO}[21,40]$, suggesting that the cNor is physiologically important for NO detoxification.

In B. japonicum, expression of nor genes in response to microaerobic conditions and $\mathrm{NO}_{3}^{-}$or a derived nitrogen oxide is controlled by a sophisticated regulatory network consisting of two linked regulatory cascades, the FixLJ/FixK ${ }_{2}-\mathrm{NnrR}$ and the RegSR/NifA systems [41]. In common with $R$. etli, but in contrast with S. meliloti, B. japonicum $\mathrm{NnrR}$ is under the control of $\mathrm{FixK}_{2}$ [42]. Thus NnrR expands the FixLJ/FixK $\mathrm{K}_{2}$ regulatory cascade by an additional control level, which integrates the nitrogen oxide signal required for maximal induction of denitrification genes (Figure 1). As observed in R. etli, the B. japonicum nirK and nor promoters exhibit slight differences with regard to their dependence on NnrR [42]. Whereas induction of nor genes is abolished completely in the absence of a functional $n n r R$ gene, microaerobic induction of $n i r K$ is retained in a $n n r R$ mutant. Maximal expression of nirK and nor genes in $B$. japonicum also needs the NifA regulatory protein [43]. In contrast, this regulator in $R$. etli has a negative effect on the expression of the nirK operon. These observations indicate that modulation of denitrification genes by NifA is different in denitrifying and non-denitrifying rhizobial species. Very recently, it has been shown that expression of B. japonicum nor $C$ is controlled by the response regulator RegR, a member of the family of two-component regulatory redox-responsive proteins present in a large number of Alphaproteobacteria [41]. However, the mechanism involved in the control of $B$. japonicum denitrification by RegSR is yet unknown.

In contrast with $P$. vulgaris $-R$. etli symbiosis, inoculation of $\mathrm{NO}_{3}{ }^{-}$-treated soya bean plants with a $B$. japonicum nor $\mathrm{C}$ mutant does not affect the level of $\mathrm{NO}$ and $\mathrm{LbNO}$ complexes within nodules, so there must be other systems that remove $\mathrm{NO}$ in the nodule [44]. Recent findings have demonstrated that hypoxic conditions provoked by flooding are required to demonstrate a role of $B$. japonicum $\mathrm{cNor}$ in $\mathrm{NO}$ reduction in nodules [21].

To identify other NO-detoxifying systems in $B$. japonicum, a search on the $B$. japonicum USDA110 genome sequence (http://genome.kazusa.or.jp/rhizobase/) was performed. This revealed a putative $\mathrm{sdHb}, \mathrm{Bjgb}$, encoded by the gene blr2807, which has a high identity with sdHbs from Vitreoscilla stercoraria and Campylobacter jejuni which are implicated in NO detoxification $[2,45,46]$. B. japonicum blr2807 is included in a gene cluster containing a putative ABC (ATP-binding cassette)-nitrate transporter, (blr2803-
Figure 2 | Growth curves of wild-type and mutant B. japonicum under microaerobic conditions

Microaerobic $\left(2 \% \mathrm{O}_{2}\right)$ growth curves of wild-type B. joponicum USDA110 $(\mathbf{A})$, and the norc $(\mathbf{B})$ and bjgb $(\mathbf{C})$ mutants in Bergersen minimum medium in the absence $(\boldsymbol{\bullet})$, and the presence of $0.5 \mathrm{mM} \mathrm{SNP}(\square)$ or $1 \mathrm{mM} \mathrm{SNP}(\Delta)$. NO was added at the time indicated by the arrow and the results are means \pm S.D. representative of three independent experiments. O.D. $=$ attenuance $\left(D_{600}\right)$
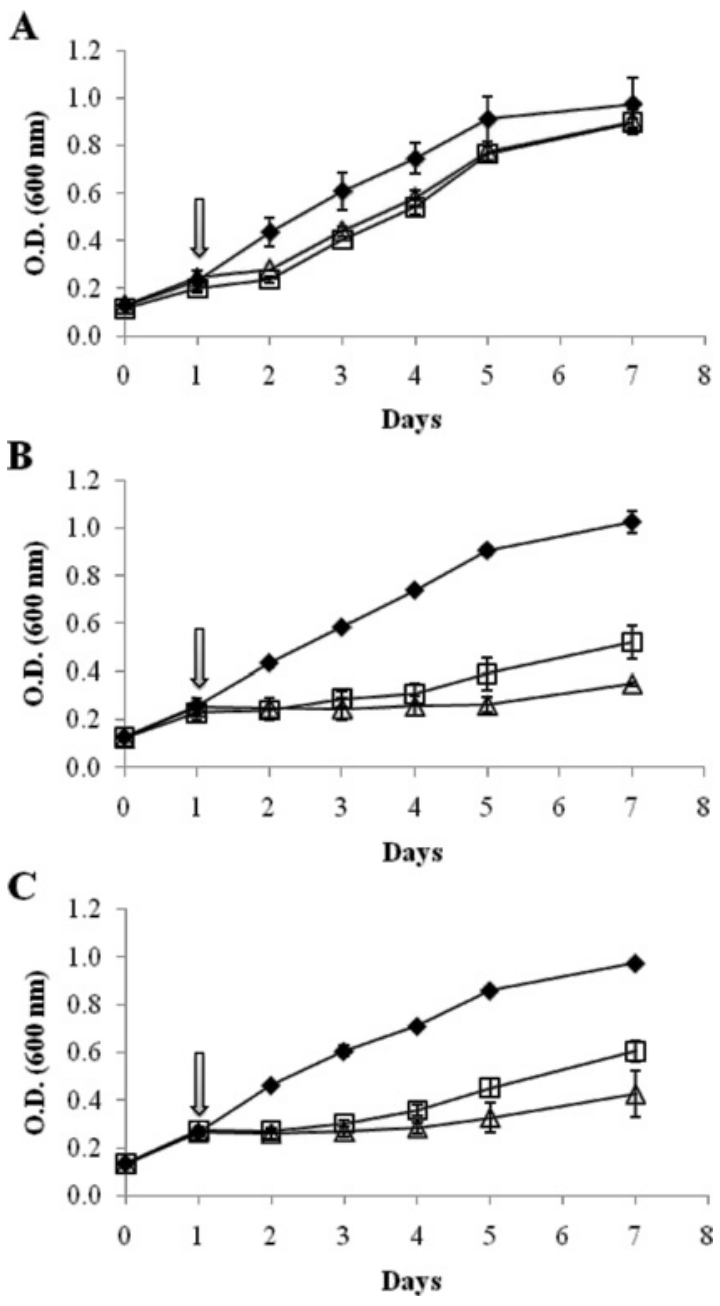

5), a nitrite extrusion protein (blr2806), a putative FADand $\mathrm{NAD}(\mathrm{P}) \mathrm{H}$-binding reductase protein (blr2808) and the large catalytic subunit, NasA, from the assimilatory nitrate reductase (blr2809) [47]. In order to investigate the involvement of $\mathrm{Bjgb}$ in the $\mathrm{NO}$ response, we constructed a deletion mutant lacking the blr2807 gene and tested its sensitivity to the NO donor SNP. The sensitivity of the bjgb mutant to SNP was compared with that of a nor $C$ mutant and the wild-type strain. Addition of SNP after $24 \mathrm{~h}$ of growth under microaerobic conditions $\left(2 \% \mathrm{O}_{2}\right)$ led to a transient arrest of cell growth in wild-type cells which was restored after $24 \mathrm{~h}$ (Figure 2A). However, the norC or the bjgb mutants showed a substantially longer period of microaerobic growth inhibition of $\sim 72 \mathrm{~h}$ after addition of either 0.5 or $1 \mathrm{mM} \mathrm{SNP}$ to the cultures (Figures 2B and 2C). These results revealed 
Table 1 | Expression data of $B$. japonicum blr2803-blr2809 genes in cells grown under different $\mathrm{O}_{2}$ concentrations

Gene nomenclature and protein description is according to Kaneko et al. [51]. Normalized signal intensities were detected in transcriptomics experiments of $B$. japonicum cells grown under free-living, oxic $\left(21 \% \mathrm{O}_{2}\right)$, micro-oxic $\left(0.5 \% \mathrm{O}_{2}\right)$ and anoxic conditions with nitrate [48,50].

Signal intensities (mean \pm S.D.)

\begin{tabular}{llccc}
\cline { 3 - 5 } Gene & Description & 0xic & Micro-oxic & Anoxic \\
\hline blr2803 & ABC transporter nitrate-binding protein & $152 \pm 57$ & $129 \pm 43$ & $364 \pm 97$ \\
blr2804 & ABC transporter permease protein & $160 \pm 75$ & $158 \pm 40$ & $287 \pm 73$ \\
blr2805 & ABC transporter ATP-binding protein & $152 \pm 64$ & $129 \pm 32$ & $312 \pm 86$ \\
blr2806 & Nitrite extrusion protein & $76 \pm 21$ & $78 \pm 32$ & $780 \pm 287$ \\
blr2807 & SdHb (Bjgb) & $98 \pm 28$ & $124 \pm 56$ & $390 \pm 111$ \\
blr2808 & FAD- and NAD(P)H-binding reductase & $20 \pm 9$ & $21 \pm 36$ & $179 \pm 66$ \\
blr2809 & Assimilatory nitrate reductase large subunit & $105 \pm 52$ & $74 \pm 96$ & $309 \pm 82$
\end{tabular}

the importance of cNor and Bjgb for NO detoxification in $B$. japonicum under free-living conditions. The symbiotic properties of the bjgb mutant on soya bean plants grown under normoxic or hypoxic conditions are currently under investigation.

Similarly to other bacterial $\mathrm{Hbs}$, Bjgb might express $\mathrm{NO}$ reductase activity to $\mathrm{N}_{2} \mathrm{O}$ or denitrosylase ('dioxygenase') activity to $\mathrm{NO}_{3}{ }^{-}$under micro-oxic free-living conditions or inside the nodules. For both activities, electrons from $\mathrm{NAD}(\mathrm{P}) \mathrm{H}$ might be delivered via the flavin protein encoded by blr2808. However, the contribution of those activities as well as the role of blr2808 (FAD-protein) in NO detoxification needs to be demonstrated.

We have performed a comparative analysis of expression of the blr2803-blr2809 gene cluster by looking at previous genome-wide transcription profiling of $B$. japonicum cells grown oxically, micro-oxically $\left(0.5 \% \mathrm{O}_{2}\right)$ or anoxically with $\mathrm{NO}_{3}{ }^{-}$[48-50]. We found that expression of these genes is significantly induced ( $\sim 2-10$-fold) in cells grown anoxically in comparison with cells grown oxically or micro-oxically (Table 1). The basal expression of blr2807 under microoxic conditions supports the phenotypic results showed in Figure 2, and suggests a role for this gene in NO detoxification under micro-oxic conditions. The putative involvement of blr2807 in NO detoxification under denitrifying conditions is, at the moment, unknown.

Putative FNR-type binding sites are present in the promoter regions of the gene cluster containing blr2807 (results not shown), indicating that low $\mathrm{O}_{2}$ concentrations are required to induce the expression of the blr2803-blr2809 gene cluster. Since maximal expression of this gene cluster was observed under $\mathrm{NO}_{3}{ }^{-}$-dependent anaerobic growth conditions, we might speculate that $\mathrm{NO}_{3}{ }^{-}$or a nitrogen oxide derived from its reduction are also required to induce expression of blr2803-blr2809 genes. The regulation of this gene cluster is currently under investigation.

\section{Funding}

This work was supported by Junta de Andalucra [grant number CVI-3177] and the Ministerio de Ciencia e Innovación [grant number AGL2010-18607] and partially funded by Fondo Europeo de Desarrollo Regional and by Ciencia y Tecnología para el Desarrollo [grant number 107PIC0312]. Support from the Junta de Andalucía [grant number BI0-275] is also acknowledged. J.J.C. was supported by a fellowship from the Consejo Superior de Investigaciones Científicas, programme JAE-Predoc.

\section{References}

1 Hughes, M.N. (2008) Chemistry of nitric oxide and related species Methods Enzymol. 436, 3-19

2 Mills, P.C., Rowley, G., Spiro, S., Hinton, J.C.D. and Richardson, D.J. (2008) A combination of cytochrome $c$ nitrite reductase ( $\mathrm{NrfA}$ ) and flavorubredoxin (NorV) protects Salmonello enterica serovar Typhimurium against killing by NO in anoxic environments. Microbiology 154, 1218-1228

3 Pittman, M.S., Elvers, K.T., Lee, L., Jones, M.A., Poole, R.K., Park, S.F. and Kelly, D.J. (2007) Growth of Compylobacter jejuni on nitrate and nitrite: electron transport to NapA and NrfA via NrfH and distinct roles for NifA and the globin Cgb in protection against nitrosative stress. Mol. Microbiol. 63, 575-590

4 Poole, R.K. (2005) Nitric oxide and nitrosative stress tolerance in bacteria. Biochem. Soc. Trans. 33, 176-180

5 Pullan, S.T., Monk, C.E., Lee, L. and Poole, R.K. (2008) Microbial responses to nitric oxide and nitrosative stress: growth, "omic," and physiological methods. Methods Enzymol. 437, 499-519

6 Spiro, S. (2011) Nitric oxide metabolism: physiology and regulatory mechanisms. In Nitrogen Cycling in Bacteria (Moir, J., ed.), pp. 177-197, Caister Academic Press, Norwich

7 van Wonderen, J.H., Burlat, B., Richardson, D.J., Cheesman, M.R. and Butt, J.N. (2008) The nitric oxide reductase activity of cytochrome $c$ nitrite reductase from Escherichio coli. J. Biol. Chem. 283, 9587-9594

8 Spiro, S. (2007) Regulators of bacterial responses to nitric oxide. FEMS Microbiol. Rev. 31, 193-211

9 Cruz-Ramos, H., Crack, J., Wu, G., Hughes, M.N., Scott, C., Thomson, A.J. Green, J. and Poole, R.K. (2002) NO sensing by FNR: regulation of the Escherichio coli NO-detoxifying flavohaemoglobin, Hmp. EMBO J. $\mathbf{2 1}$ 3235-3244

10 Tucker, N.P., D’Autréaux, B., Yousafzai, F.K., Fairhurst, S.A., Spiro, S. and Dixon, R. (2008) Analysis of the nitric oxide-sensing non-heme iron center in the NorR regulatory protein. J. Biol. Chem. 283, 908-918

11 Tucker, N.P., Ghosh, T., Bush, M., Zhang, X. and Dixon, R. (2010) Essential roles of three enhancer sites in $\sigma^{54}$-dependent transcription by the nitric oxide sensing regulatory protein NorR. Nucleic Acids Res. 38, 1182-1194

12 Tucker, N.P., Le Brun, N.E., Dixon, R. and Hutchings, M.I. (2010) There's NO stopping NsrR, a global regulator of the bacterial NO stress response. Trends Microbiol. 18, 149-156 
13 Oldroyd, G.E.D. and Downie, J.A. (2008) Coordinating nodule morphogenesis with rhizobial infection in legumes. Annu. Rev. Plant Biol. 59, 519-546

14 Bedmar, E.J., Robles, E.F. and Delgado, M.J. (2005) The complete denitrification pathway of the symbiotic, nitrogen-fixing bacterium Brodyrhizobium joponicum. Biochem. Soc. Trans. 33, 141-144

15 Delgado, M.J., Casella, S. and Bedmar, E.J. (2007) Denitrification in rhizobia-legume symbiosis. In Biology of the Nitrogen Cycle (Bothe, $\mathrm{H}$. Ferguson, S.J. and Newton, W.E., eds), pp. 83-92, Elsevier, Amsterdam

16 Meilhoc, E., Boscari, A., Bruand, C., Puppo, A. and Brouquisse, R. (2011) Nitric oxide in legume-rhizobium symbiosis. Plant Sci. 181, 573-581

17 Sánchez, C., Bedmar, E.J. and Delgado, M.J. (2011a) Denitrification in legume-associated endosymbiotic bacteria. In Nitrogen Cycling in Bacteria (Moir, J., ed.), pp. 197-210, Caister Academic Press, Norwich

18 Baudouin, E., Pieuchot, L., Engler, G., Pauly, N. and Puppo, A. (2006) Nitric oxide is formed in Medicago truncatula-Sinorhizobium meliloti functional nodules. Mol. Plant Microbe Interact. 19, 970-975

19 Meakin, G.E., Bueno, E., Jepson, B., Bedmar, E.J., Richardson, D.J. and Delgado, M.J. (2007) The contribution of bacteroidal nitrate and nitrite reduction to the formation of nitrosylleghaemoglobin complexes in soybean root nodules. Microbiology 153, 411-419

20 Pii, Y., Crimi, M., Cremonese, G., Spena, A. and Pandolfini, T. (2007) Auxin and nitric oxide control indeterminate nodule formation. BMC Plant Biol. 7, 21

21 Sánchez, C., Gates, A.J., Meakin, G.E., Uchiumi, T., Girard, L., Richardson, D.J., Bedmar, E.J. and Delgado, M.J. (2010) Production of nitric oxide and nitrosylleghemoglobin complexes in soybean nodules in response to flooding. Mol. Plant Microbe Interact. 23, 702-711

22 Besson-Bard, A., Courtois, C., Gauthier, A., Dahan, J., Dobrowolska, G., Jeandroz, S., Pugin, A. and Wendehenne, D. (2008) Nitric oxide in plants: production and cross-talk with $\mathrm{Ca}^{2}+$ signaling. Mol. Plant 1, 218-228

23 Moreau, M., Lindermayr, C., Durner, J. and Klessig, D.F. (2010) N0 synthesis and signaling in plants: where do we stand? Physiol. Plant. 138, 372-383

24 Cueto, M., Hernández-Perera, 0., Martín, R., Bentura, M.L., Rodrigo, J., Lamas, S. and Golvano, M.P. (1996) Presence of nitric oxide synthase activity in roots and nodules of Lupinus albus. FEBS Lett. 398, 159-164

25 Horchani, F., Prévot, M., Boscari, A., Evangelisti, E., Meilhoc, E., Bruand, C., Raymond, P., Boncompagni, E., Aschi-Smiti, S., Puppo, A. and Brouquisse, R. (2011) Both plant and bacterial nitrate reductases contribute to nitric oxide production in Medicago truncatula nitrogen-fixing nodules. Plant Physiol. 155, 1023-1036

26 del Giudice, J., Cam, Y., Damiani, I., Fung-Chat, F., Meilhoc, E., Bruand, C., Brouquisse, R., Puppo, A. and Boscari, A. (2011) Nitric oxide is required for an optimal establishment of the Medicago truncatulo-Sinorhizobium meliloti symbiosis. New Phytol. 191, 405-417

27 Shimoda, Y., Shimoda-Sasakura, F., Kucho, K., Kanamori, N., Nagata, M., Suzuki, A., Abe, M., Higashi, S. and Uchiumi, T. (2009) Overexpression of class 1 plant hemoglobin genes enhances symbiotic nitrogen fixation activity between Mesorhizobium loti and Lotus joponicus. Plant J. $\mathbf{5 7}$ 254-263

28 Tominaga, A., Nagata, M., Futsuki, K., Abe, H., Uchiumi, T., Abe, M. Kucho, K., Hashiguchi, M., Akashi, R., Hirsch, A.M. et al. (2009) Enhanced nodulation and nitrogen fixation in the abscisic acid low-sensitive mutant enhanced nitrogen fixation1 of Lotus japonicus. Plant Physiol. 151, 1965-1976

29 Meilhoc, E., Cam, Y., Skapski, A. and Bruand, C. (2010) The response to nitric oxide of the nitrogen-fixing symbiont Sinorhizobium meliloti. Mol. Plant Microbe Interact. 23, 748-759

30 Bobik, C., Meilhoc, E. and Batut, J. (2006) Fix): a major regulator of the oxygen limitation response and late symbiotic functions of Sinorhizobium meliloti. J. Bacteriol. 188, 4890-4902

31 Gilles-Gonzalez, M.A., Gonzalez, G., Sousa, E.H.S. and Tuckerman, J. (2008) Oxygen-sensing histidine-protein kinases: assays of ligand binding and turnover of response-regulator substrates. Methods Enzymol. 437, 173-189

32 de Bruijn, F.J., Rossbach, S., Bruand, C. and Parrish, J.R. (2006) A highly conserved Sinorhizobium meliloti operon is induced microaerobically via the FixLJ system and by nitric oxide (NO) via NnrR. Environ. Microbiol. 8 , $1371-1381$

33 Justino, M.C., Vicente, J.B., Teixeira, M. and Saraiva, L.M. (2005) New genes implicated in the protection of anaerobically grown Escherichio coli against nitric oxide. J. Biol. Chem. 280, 2636-2643
34 Gardner, P.R. (2005) Nitric oxide dioxygenase function and mechanism of flavohemoglobin, hemoglobin, myoglobin and their associated reductases. J. Inorg. Biochem. 99, 247-266

35 Gardner, P.R. (2008) Assay and characterization of the NO dioxygenase activity of flavohemoglobins. Methods Enzymol. 436, 217-237

36 González, V., Santamaría, R.I., Bustos, P., Hernández-González, I., Medrano-Soto, A., Moreno-Hagelsieb, G., Janga, S.C., Ramírez, M.A Jiménez-Jacinto, V., Collado-Vides, J. and Dávila, G. (2006) The partitioned Rhizobium etli genome: genetic and metabolic redundancy in seven interacting replicons. Proc. Natl. Acad. Sci. U.S.A. 103, 3834-3839

37 Girard, L., Brom, S., Dávalos, A., López, O., Soberón, M. and Romero, D. (2000) Differential regulation of fixN-reiterated genes in Rhizobium etli by a novel fixL-fixK cascade. Mol. Plant Microbe Interact. 13, 1283-1292

38 Bueno, E., Gómez-Hernández, N., Girard, L., Bedmar, E.J. and Delgado, M.J. (2005) Function of the Rhizobium etli CFN42 nirk gene in nitrite metabolism. Biochem. Soc. Trans. 33, 162-163

39 Gómez-Hernández, N., Reyes-González, A., Sánchez, C., Mora, Y., Delgado, M.J. and Girard, L. (2011) Regulation and symbiotic role of nirk and norC expression in Rhizobium etli. Mol. Plant Microbe Interact. 24, 233-245

40 Mesa, S., Velasco, L., Manzanera, M.E., Delgado, M.J. and Bedmar, E.J. (2002) Characterization of the norCBQD genes, encoding nitric oxide reductase, in the nitrogen fixing bacterium Bradyrhizobium japonicum. Microbiology 148, 3553-3560

41 Torres, M.J., Bueno, E., Mesa, S., Bedmar, E.J. and Delgado, M.J. (2011) Emerging complexity in the denitrification regulatory network of Bradyrhizobium joponicum. Biochem. Soc. Trans. 39, 284-288

42 Mesa, S., Bedmar, E.J., Chanfon, A., Hennecke, H. and Fischer, H.-M. (2003) Bradyrhizobium joponicum NnrR, a denitrification regulator, expands the FixLJ-FixK 2 regulatory cascade. J. Bacteriol. 185, 3978-3982

43 Bueno, E., Mesa, S., Sanchez, C., Bedmar, E.J. and Delgado, M.J. (2010) NifA is required for maximal expression of denitrification genes in Bradyrhizobium japonicum. Environ. Microbiol. 12, 393-400

44 Meakin, G.E., Jepson, B.J.N., Richardson, D.J., Bedmar, E.J. and Delgado, M.J. (2006) The role of Bradyrhizobium japonicum nitric oxide reductase in nitric oxide detoxification in soya bean root nodules. Biochem. Soc. Trans. 34, 195-196

45 Elvers, K.T., Wu, G., Gilberthorpe, N.J., Poole, R.K. and Park, S.F. (2004) Role of an inducible single-domain hemoglobin in mediating resistance to nitric oxide and nitrosative stress in Compylobocter jejuni and Compylobacter coli. J. Bacteriol. 186, 5332-5341

46 Frey, A.D., Bailey, J.E. and Kallio, P.T. (2000) Expression of Alcaligenes eutrophus flavohemoprotein and engineered Vitreoscillo hemoglobin-reductase fusion protein for improved hypoxic growth of Escherichio coli. Appl. Environ. Microbiol. 66, 98-104

47 Sánchez, C., Cabrera, J.J., Gates, A.J., Bedmar, E.J., Richardson, D.J. and Delgado, M.J. (2011) Nitric oxide detoxification in the rhizobia-legume symbiosis. Biochem. Soc. Trans. 39, 184-188

48 Hauser, F., Pessi, G., Friberg, M., Weber, C., Rusca, N., Lindemann, A. Fischer, H.M. and Hennecke, H. (2007) Dissection of the Bradyrhizobium joponicum NifA $+\sigma^{54}$ regulon, and identification of a ferredoxin gene $(f d x N)$ for symbiotic nitrogen fixation. Mol. Genet. Genomics 278 255-271

49 Mesa, S., Hauser, F., Friberg, M., Malaguti, E., Fischer, H.M. and Hennecke, H. (2008) Comprehensive assessment of the regulons controlled by the FixLJ-FixK 2 -FixK 1 cascade in Bradyrhizobium joponicum. J. Bacteriol. 190, 6568-6579

50 Pessi, G., Ahrens, C.H., Rehrauer, H., Lindemann, A., Hauser, F., Fischer, H.M. and Hennecke, H. (2007) Genome-wide transcript analysis of Bradyrhizobium joponicum bacteroids in soybean root nodules. Mol. Plant Microbe Interact. 20, 1353-1363

51 Kaneko, T., Nakamura, Y., Sato, S., Minamisawa, K., Uchiumi, T., Sasamoto, S., Watanabe, A., Idesawa, K., Iriguchi, M., Kawashima, K. et al. (2002) Complete genomic sequence of nitrogen-fixing symbiotic bacterium Bradyrhizobium joponicum USDA110. DNA Res. 9 189-197

Received 1 September 2011 doi:10.1042/BST20110732 